\title{
Teenage girls and venereal disease prophylaxis
}

\author{
WILLIAM L. YARBER \\ From Purdue University, West Lafayette, Indiana, USA
}

SUMMARY One of the main aims of venereal disease education is to encourage the use of prophylactic techniques by sexually-active persons. To do this educators must convey information about prophylaxis that is relevant. This study was designed to assess the knowledge, attitude, and behaviour regarding prophylaxis of a group of 200 American adolescent girls. The findings suggest areas of prophylaxis that should be emphasised and ways that might encourage the acceptance and use of prophylactic measures. The study showed there were some misunderstandings and that it was important, for example to clarify the relationship of the oral contraceptive to possible venereal disease infection. Education involving both the cognitive and affective domains was indicated by the partial acceptance of the use of the condom, particularly by persons who had more than one partner.

\section{Introduction}

One of the main aims of venereal disease education is to encourage the use of protective/preventive measures (prophylaxis), so that the sexually-active person exposed to infection may modify his/her behaviour and reduce the likelihood of venereal disease contraction (Schwartz, 1963; American Social Health Association, 1975a).

The use of prophylaxis is particularly important for those groups in which the incidence of diseases is highest. One group that is especially vulnerable is the young adult, in whom venereal disease infection is most often reported (American Social Health Association, 1975b). Such an outcome must partly depend on accurate, relevant knowledge being given on prophylaxis by those responsible for venereal disease education. To determine what concepts should be presented it was necessary to find out what knowledge the study group had and what their behaviour and relative attitudes were to venereal disease protective/preventive measures. These data could help educators to determine the concepts that most needed to be emphasised in future instruction.

\section{THE PROBLEM}

This pilot investigation set out to answer the following questions:

Address for reprints: W. L. Yarber, Assistant Professor of Health Education, Purdue University, West Lafayette, Indiana 47907, USA

Received for publication 5 August 1976
1. Did the population have an accurate knowledge of venereal disease prophylactic measures? And how did the population rate the effectiveness of preventive measures?

2. What were the attitudes of the population towards the condom?

3. Were measures consciously taken to prevent the contraction of a venereal disease by members of the population who have participated in sexual intercourse? If so, what measures were used most frequently?

4. How did members of the population plan to prevent the contraction of venereal disease in the future?

A main aim of the study was to determine if any relationship existed between these questions and selected characteristics of the population (the $\chi^{2}$ test was conducted at the 0.05 alpha level). It also sought information for public health educators and other medical personnel dealing with similar populations to help in the planning of venereal disease education.

\section{Source of data}

The population of the study was limited to 200 single (and never married) adolescent girls. The girls were drawn from those persons participating in educational sessions at the Planned Parenthood Association of Indianapolis, and those attending the Venereal Diseases Clinic of the Wishard Memorial Hospital, Indianapolis. These sources were chosen because the investigators desired to examine the problems of girls who were largely sexually active; $182(91 \%)$ of 
them were participating in sexual intercourse at the time of the study. As attention is currently being paid to the problems of women, it was felt that a study dealing with teenage girls would be appropriate. Table 1 gives details of these girls.

Table 1 Characteristics of the study population

\begin{tabular}{|c|c|c|}
\hline Variable & Frequency & $\%$ \\
\hline \multicolumn{3}{|l|}{ Age $(N=200)$ : } \\
\hline 13 or younger & 5 & $2 \cdot 5$ \\
\hline 14 & 7 & $3 \cdot 5$ \\
\hline 15 & 20 & $10 \cdot 0$ \\
\hline 16 & 55 & $27 \cdot 5$ \\
\hline 17 & 79 & $39 \cdot 5$ \\
\hline 18 & 33 & $16 \cdot 5$ \\
\hline 19 & 1 & $0 \cdot 5$ \\
\hline \multicolumn{3}{|l|}{ Race $(N=199)$ : } \\
\hline White & 137 & $68 \cdot 8$ \\
\hline Black & 59 & $29 \cdot 7$ \\
\hline Spanish-American & 2 & $1 \cdot 0$ \\
\hline American Indian & $\mathbf{0}$ & 0.0 \\
\hline Other & 1 & 0.5 \\
\hline \multicolumn{3}{|l|}{ Present frequency of intercourse $(N=200)$ : } \\
\hline None & 18 & $9 \cdot 0$ \\
\hline Seldom (less than once a month) & 33 & $16 \cdot 5$ \\
\hline Once or twice a month & 39 & $19 \cdot 5$ \\
\hline Once a week & 30 & $15 \cdot 0$ \\
\hline Twice a week & 32 & $16 \cdot 0$ \\
\hline Three times a week & 25 & $12 \cdot 5$ \\
\hline Four or more times a week & 23 & $11 \cdot 5$ \\
\hline \multicolumn{3}{|l|}{ Number of male sexual partners $(N=198)$ : } \\
\hline None & 18 & $8 \cdot 7$ \\
\hline One & 82 & $41 \cdot 6$ \\
\hline Two & 30 & $15 \cdot 2$ \\
\hline Threo & 26 & $13 \cdot 2$ \\
\hline Four & 11 & $5 \cdot 6$ \\
\hline Five & 4 & $2 \cdot 0$ \\
\hline Six or more & 27 & $13 \cdot 7$ \\
\hline \multicolumn{3}{|l|}{ Venereal disease $(N=200)$ : } \\
\hline Have contracted gonorrhoea and/or syphilis & 20 & $10 \cdot 0$ \\
\hline \multicolumn{3}{|l|}{ Grades usually earned in school $(N=198)$ : } \\
\hline Excellent & 13 & $6 \cdot 6$ \\
\hline Above average & 61 & $30 \cdot 8$ \\
\hline Average & 115 & $58 \cdot 1$ \\
\hline Below average & 9 & $4 \cdot 5$ \\
\hline \multicolumn{3}{|l|}{ Father's education $(N=193)$ : } \\
\hline Graduated from college & 31 & $16 \cdot 1$ \\
\hline Graduated from high school but not college & 100 & $51 \cdot 8$ \\
\hline Did not graduate from high school & 62 & $32 \cdot 1$ \\
\hline \multicolumn{3}{|l|}{$\begin{array}{l}\text { Received VD information in junior and/or senior } \\
\text { high school }(N=197) \text { : }\end{array}$} \\
\hline $\begin{array}{l}\text { Yes } \\
\text { No }\end{array}$ & 160 & $81 \cdot 2$ \\
\hline No & 37 & $18 \cdot 8$ \\
\hline
\end{tabular}

\section{Collection of data}

The data were collected during the first 10 months of 1975 , and were obtained by the use of a questionnaire. The questionnaire was a modified version of one used in previous studies by one of the investigators (Yarber, 1974; Yarber and Williams, 1975). The main modifications were the use of simpler vocabulary and elimination of questions unrelated to this study.

Interpretations of the findings should take into account the data collection procedure and the questionnaire used.

\section{Findings and discussion}

KNOWLEDGE OF VD PROPHYLACTIC MEASURES The opinion of the population on the effectiveness of venereal disease prophylactic methods is presented in Table 2. The list of measures chosen for this and other related questions contained venereal disease prophylactic measures discussed in health science literature (Chiappa and McHugh, 1973; Kogan, 1974; Bender, 1975; Brecher, 1975) and selected contraceptive techniques. Only those methods which the teenage girl or her partner could obtain and use without much difficulty were listed.

There was a lack of understanding of venereal disease prophylaxis as all four ratings were chosen for each of the listed measures. Nevertheless, four of the techniques that are generally considered among the most effective prophylactic measures (condom, limiting sexual intercourse to one partner, careful selection of partners, and inspection for sores or penile discharge) were chosen by $64 \%{ }^{*}$ of the population if the categories 'very effective' and 'somewhat effective' are combined. The table also revealed that only a few of the girls rated the other more effective measures as being either 'very effective' or 'somewhat effective'.

The analysis of the ratings of the effectiveness of the birth control pill revealed an interesting finding: nearly one-quarter of the population (47) rated the pill as either an 'effective' or 'somewhat effective' venereal disease prophylactic.

The $\chi^{2}$ test was conducted between the characteristics of the population (Table 1) and two important items listed in Table 2. A significant correlation was established with only one population characteristic, that of age, when the effectiveness of the condom was considered. There was a tendency $\left(\chi_{12}{ }^{2}=24 \cdot 81\right.$, $P=0.0157$ ) for the younger girls to indicate more frequently the 'very effective' and ' $I$ do not know' categories, and for the older girls to indicate more frequently the 'somewhat effective' and 'not effective at all' categories. Similarly, only one significant correlation was found when the population characteristics were compared with the responses to the birth control effectiveness question. There was a tendency $\left(\chi_{\theta}^{2}=24.77, P=0.0032\right)$ for those who were White

*The percentages reported in interpretations like this throughout the study are actually the percentage of the population who responded to the particular question. 
Table 2 Population opinion of the effectiveness of possible venereal disease prophylactic measures*

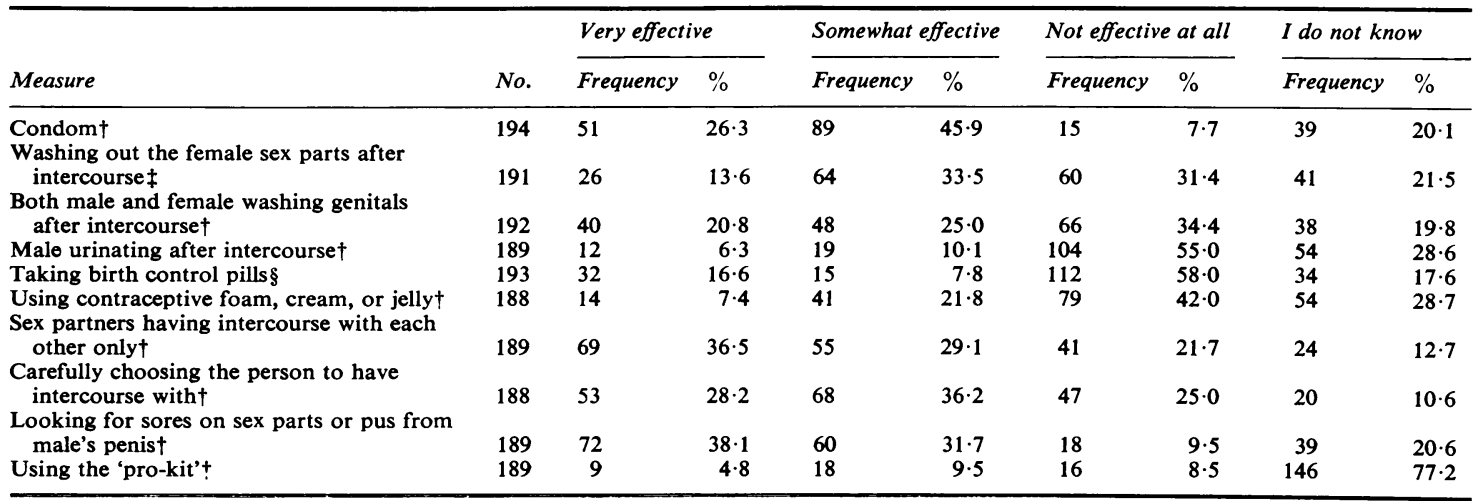

*Exact wording of question: 'How effective is each of the below in preventing a person from getting VD?'

tListed in the literature as a method for reducing the chances of venereal disease infection.

$\ddagger$ Listed as a possible effective prophylactic technique, but should not be done frequently.

$\S$ Not effective for preventing venereal disease infection.

to choose more frequently the 'not effective at all' category, while the Black subjects chose more frequently the 'very effective' and 'somewhat effective' categories, for the birth control pill question.

\section{ATTITUDE TOWARDS CONDOM}

Apart from abstinence, the main way to prevent venereal disease infection is by selected sexual behaviour. However, for people who choose to be less discriminate in their choice of sexual partner, the use of a prophylactic technique (for example, condom) is imperative (Jones et al., 1974).

Despite the fact that public health officials are making strong efforts to increase knowledge on the availability and effectiveness of the condom, its use is not widespread. The acceptance of the condom by sexually-active persons is the key factor.

Indices of the population's attitude towards the condom are presented in Table 3. A moderate acceptance of the condom was revealed in the responses to question no. 1 , as only 47 girls (about one-quarter) said that they would get condoms if they could be easily obtained, $33 \%$ said they were undecided, and about $41 \%$ stated that they did not wish to obtain a condom. $\chi^{2}$ test results showed no significant relationships between the responses to question no. 1 and the characteristics of the population.

The responses to question no. 2 also revealed only a partial acceptance of the condom; $43(23 \%)$ agreed with the use of it for sexual intercourse, while $49 \cdot 7 \%$ did not agree. The $\chi^{2}$ test revealed significant correlations between the responses to question no. 2 and three population characteristics-race, frequency of intercourse, and number of intercourse partners. There was a tendency $\left(\chi_{6}{ }^{2}=16 \cdot 15, \mathrm{P}=0.0129\right)$ for those who were White more frequently to wish not to use condoms for intercourse and for those who were Black to agree to use them. For the frequency of intercourse correlation, there was a tendency $\left(\chi_{12}{ }^{2}=30.53, P=0.0023\right)$ for those who indicated intercourse frequency as once or twice a month and once a week to accept the use of condoms, a tendency for girls who never or seldom participated in sexual intercourse to be undecided about condoms,

Table 3 Attitude towards the condom

\begin{tabular}{|c|c|c|c|c|c|c|}
\hline \multirow{2}{*}{ Question } & \multicolumn{2}{|l|}{ I agree } & \multicolumn{2}{|c|}{ I am undecided } & \multicolumn{2}{|l|}{ I disagree } \\
\hline & Frequency & $\%$ & Frequency & $\%$ & Frequency & $\%$ \\
\hline \multicolumn{7}{|l|}{ 1. I would get condoms (rubbers) if I could get them easily and with } \\
\hline $\begin{array}{l}\text { little cost or free }(N=180) \\
\text { 2. I do not (or would not) mind using the condom during intercourse }\end{array}$ & 47 & $26 \cdot 1$ & 60 & $33 \cdot 3$ & 73 & $40 \cdot 6$ \\
\hline $\begin{array}{l}(N=185) \\
\text { 3. It is } O K \text { for a girl to carry condoms in her purse to use for intercourse }\end{array}$ & 43 & $23 \cdot 0$ & 51 & $27 \cdot 3$ & 93 & $49 \cdot 7$ \\
\hline $\begin{array}{l}(\mathrm{N}=186) \\
\text { 4. It is } \mathrm{OK} \text { for a boy to carry condoms in his wallet to use for intercourse }\end{array}$ & 70 & $37 \cdot 6$ & 45 & $24 \cdot 2$ & 71 & $38 \cdot 2$ \\
\hline$(\mathrm{N}=189)$ & 136 & $72 \cdot 0$ & 28 & $14 \cdot 8$ & 25 & $13 \cdot 2$ \\
\hline
\end{tabular}


and a tendency for girls participating in sexual intercourse four or more times a week to disagree on the use of condoms. For the number of intercourse partners* correlation, there was a tendency $\left(\chi_{10}{ }^{2}=22.27, P=0.0138\right)$ for the girls who indicated one intercourse partner to agree more frequently with the use of a condom, a tendency for the girls who indicated three intercourse partners to be undecided, and a tendency for the girls who indicated six or more partners to disagree about using a condom.

Responses to questions nos 3 and 4 may reveal a 'sexist' attitude towards the condom. Nearly twice as many subjects (136 compared to 70 ) felt that it was acceptable for the man to carry a condom in his wallet but fewer felt that it was acceptable for the girl to carry one in her purse. No significant correlation was found between the responses to question no. 3 and characteristics of the population; but there was a significant correlation between the responses to question no. 4 and one population characteristic. There was a tendency $\left(\chi_{6}{ }^{2}=13.60, P=0.0344\right)$ for the White girls to be undecided about the man carrying a condom while the Black girls agreed more frequently that the man could carry a condom.

\section{USE OF PROPHYLACTIC METHODS}

In response to the question, 'Have you or your sex partner ever done anything on purpose to keep from getting VD?', 64 subjects $(35.2 \%$ of those who were sexually active) responded 'yes'. The $\chi^{2}$ test was conducted between the use of prophylactic measures

*It is interesting to note that a significant correlation was established between the contraction of gonorrhoea and/or syphilis and the number of intercourse partners $\left(\chi_{10^{2}}=19.89, P=0.0303\right)$ : there was a tendency for those subjects who reported gonorrhoea and/or syphilis infection to indicate intercourse experience with a greater number of men than those who did not report infection. and the contraction of gonorrhoea and/or syphilis: a significant correlation was established $\left(\chi_{6}^{2}=\right.$ 13.49, $P=0.0358)$. Surprisingly, there was a tendency for those who reported having contracted gonorrhoea and/or syphilis to indicate more frequently that they used prophylactic measures and for the subjects who did not report infection to indicate more frequently that they did not use prophylactic techniques.

The prophylactic measures used are presented in Table 4. Four methods were used about twice as frequently as other techniques: each of these (condom, washing after intercourse, intercourse with sex partner only, and douching) is considered an effective preventive technique.

It is interesting to note that despite the fact that the condom was only partially accepted by the population, $50 \%$ of those who used prophylactic measures used the condom.

\section{PLANNED USE OF PROPHYLACTIC MEASURES}

The techniques that the study group planned to use in the future to prevent venereal disease contraction are presented in Table 4. Among the methods that involve sexual behaviour ( 28 girls indicated that they do not plan to have sexual intercourse), $53 \%$ of the population (106) stated that they would have intercourse only with their sex partner. If both partners remain faithful and neither brings a venereal disease into the relationship, this is the most effective prophylactic technique other than abstinence.

\section{Conclusions}

Although the findings of this research should not be taken as being representative of adolescent girls as a whole, the data can be useful in determining

Table 4 Previous and planned use of possible venereal disease prophylactic measures $(N=200)$

\begin{tabular}{|c|c|c|c|c|c|}
\hline \multirow{2}{*}{ Method $\dagger$} & \multicolumn{3}{|c|}{ Previous use* } & \multicolumn{2}{|c|}{ Planned use $\ddagger$} \\
\hline & Frequency & $\% \ddagger$ & $\% \S$ & Frequency & $\%$ \\
\hline $\begin{array}{l}\text { Condom } \\
\text { Male urinates after intercourse } \\
\text { Wash sex parts after intercourse } \\
\text { Use contraceptive foam, cream, or jelly } \\
\text { Look for sores on male and female sex parts and pus from the penis } \\
\text { Birth control pills } \\
\text { Wash out vagina after intercourse } \\
\text { 'Pro-kit' or similar kit } \\
\text { Intercourse with sex partner only } \\
\text { Careful selection of sex partners } \\
\text { Not have intercourse } \\
\text { Other }\end{array}$ & $\begin{array}{r}32 \\
11 \\
28 \\
11 \\
15 \\
13 \\
29 \\
1 \\
30 \\
11 \\
-1\end{array}$ & $\begin{array}{r}50 \cdot 0 \\
17 \cdot 2 \\
43 \cdot 7 \\
17 \cdot 2 \\
23 \cdot 4 \\
20 \cdot 3 \\
45 \cdot 2 \\
1 \cdot 6 \\
45 \cdot 2 \\
17 \cdot 2 \\
-1 \cdot 6\end{array}$ & $\begin{array}{r}17 \cdot 6 \\
6 \cdot 0 \\
15 \cdot 3 \\
6 \cdot 0 \\
8 \cdot 2 \\
7 \cdot 1 \\
15.9 \\
0.5 \\
16 \cdot 4 \\
6.0 \\
- \\
0.5\end{array}$ & $\begin{array}{r}29 \\
22 \\
47 \\
19 \\
41 \\
47 \\
6 \\
106 \\
49 \\
28 \\
5\end{array}$ & $\begin{array}{r}14.5 \\
11 \cdot 0 \\
23.5 \\
9.5 \\
20.5 \\
\overline{23} \cdot 5 \\
3.0 \\
53 \cdot 0 \\
24.5 \\
14.0 \\
2.5\end{array}$ \\
\hline
\end{tabular}

*Exact wording of question: 'Which of the methods below have you or your sex partner used on purpose to keep from getting $V D$ ? (You may choose more than one answer.)' Only subjects who were participating in intercourse were asked this question.

†Exact wording of question: 'Assuming that you do not want to get VD, what would you do in the future to keep from getting VD? (You may choose more than one answer.)'

$\ddagger$ Calculated relative to the number of subjects (64) who reported use of preventive measures.

$\$$ Calculated relative to the number of subjects who were participating in intercourse. 
what concepts and educational strategies are desirable to convey information on venereal diseases to such people. Several findings indicate the need for further research.

Although the research revealed that nearly twothirds of the subjects considered four of the actual prophylactic measures as effective, education is still desirable as less than one-half, one-third, one-sixth, and one-sixth of the population rated washing, using contraceptive foam (etc.), using the 'pro-kit', and for the man to urinate, respectively, as either 'very effective' or 'somewhat effective' in minimising the chances of venereal disease infection. Another indication that further education was necessary was the finding that at least one-fifth of the subjects chose the categories, 'not effective at all' and 'I do not know', for the measures that are considered effective in reducing the chances of infection.

The small percentage of subjects who used prophylactic measures $(35.2 \%$ of those participating in intercourse) and the findings concerning the future use of prophylactic techniques may reveal a misunderstanding about the widespread incidence of venereal disease and how one can become infected, and/or the ignorance or rejection of the use of prophylactic measures. These misunderstandings and rejections indicate what areas of education should be emphasised for both the cognitive and affective domains. The finding that a greater use of prophylactic techniques was made by those who had contracted a venereal disease may reveal an incorrect or inconsistent use of the prophylactic techniques, or the contraction of the venereal disease might have made the subjects aware of their vulnerability.

Findings indicate a need for further education, particularly for the development of a positive attitude towards the condom. Despite the fact that the condom was rated as the second most effective preventive measure and was the most frequently used preventive technique, it was only partially accepted and less than one-fifth of the population who stated they would have intercourse in the future indicated that they planned to use the device. A need for education designed to increase the woman's acceptance of carrying a condom was revealed as it is particularly important for the woman who is indiscriminate in her sexual bəhaviour to protect herself from possible venereal disease infection. The study indicated that emphasis should be directed towards increasing the White girls' acceptance of the man carrying and using the condom for intercourse, and towards increasing condom use by girls with several intercourse partners.

The research indicated the need for education concerning the relationship of the birth control pill and venereal disease. Slightly over $40 \%$ of the population considered the oral contraceptive as either 'very effective' or 'somewhat effective' in preventing venereal disease infection; some did not know if the birth control pill prevented infection and one-fifth who reported using prophylactic measures indicated that they had used oral contraceptives to prevent venereal disease contraction. The research revealed a need for clarifying the Black girls' knowledge of the relationship of the birth control pill with venereal disease infection.

\section{References}

American Social Health Association (1975a). Today's VD Control Problem 1975, p. 26. The Association: New York.

American Social Health Association (1975b). Today's VD Control Problem 1975, pp. 16-18. The Association: New York.

Bender, S. J. (1975). VD, pp. 75-77. Brown: Iowa.

Brecher, F. A. (1975). Prevention of sexually transmitted diseases. Journal of Sex Research, 11, 318-328.

Chiappa, J., and McHugh, G. (1973). A Shortcut to Venereal Disease Education, pp. 3-4. Family Life Publications: North Carolina.

Jones, K. L., Shainberg, L. W., and Byer, C.O. (1974). VD, p. 91. Harper and Row: New York.

Kogan, B. A. (1974). Health, pp. 182-183. Harcourt, Brace, Jovanovich: New York.

Schwartz, W. F. (1963). Some pragmatic considerations in venereal disease education. Journal of School Health, 33, 164-170.

Yarber, W. L. (1974). College women and prevention of venereal disease. Journal of the American College Health Association, 22, 412-418.

Yarber, W. L., and Williams, C. E. (1975). Venereal disease prevention and a selected group of college students. Journal of the American Venereal Disease Association, 2, 17-24. 